\title{
Statistical Analysis of Fund Theses of Archival Science in China 2009-2013
}

\author{
Shui-sheng Chen \\ Wuyi University, Jiangmen, Guangdong, China
}

\begin{abstract}
Scientific research fund is an important way to research subsidized by the government, the fund theses number is an important index to evaluate the level of scientific research institutions of scientific research. Counting several aspects of distribution, fund supported level, periodicals distribution, authors, and coauthor rate by using the method of bibliometrics, to understand the development situation of archives fund theses. Analysing Chinese published on periodical full text database of fund theses, to explore the development process of archive fund thesis research in recent years, in order to provide some reference on research foundation of archives in our country.
\end{abstract}

Keywords — archives, scientific research fund, foundation papers, quantitative analysis

\section{9-2013 年我国档案学基金论文的统计分析}

\author{
陈水生 \\ 五邑大学，江门，广东，中国
}

摘 要 科研基金是政府对科研资助的重要方式, 基金论文数量是对科研机构的科研水平的重要评价指标。运用文献计量学方法, 从基金论文年代分布、基金资助级别、期刊分布、作者发文及合著率、机构分布等几方面统计，可以了解档案基金资助论文的发展状 况。通过对中国期刊全文数据库刊载的基金论文分析，探讨近年来档案基金论文研究的发展进程，以期能对我国档案学基金研究提供 一定的借鉴和参考。

关键词 档案学，科研基金，基金论文，定量分析

科研基金论文是指由国家各级政府部门，各类基金组 织和企事业单位提供科研经费而产生的研究论文[1]。基金 是政府对科研资助的重要方式, 基金论文数量是对科研机 构的科研水平的重要评价指标。对基金论文进行统计分析, 可以了解档案学基金论文的发展状况。并与刘红珠等人发 表在《档案与建设》(2008 年第 11 期)上的《1990-2007 年我国档案学基金论文的统计分析》[2] (以下简称为《分 析》)作一比较, 通过档案基金研究的新趋势、新动向, 总 结研究的成功经验，并以期能对基金资助基金研究提供一 定的借鉴和参考。

\section{1. 资料与方法}

以 2009-2013 年刊载在《中国期刊全文数据库》的基 金论文为数据源, 以“基金”为检索项，以“档案”为检索词， 检索时间截止到 2013 年底, 建立 Excel 文本, 采用文献计
量方法，从基金论文年代分布、基金资助级别、期刊分布、 作者发文及合著率、机构分布等几方面统计分析。

2. 基金论文研究现状分析

2.1 档案学基金论文数量、级别及年代分布

表 1 基金论文数量与年代分布表

\begin{tabular}{|c|c|c|c|c|c|}
\hline 年份 & 篇数 & 比例 & 年份 & 篇数 & 比例 \\
\hline 2009 & 167 & $10.37 \%$ & 2012 & 405 & $25.14 \%$ \\
\hline 2010 & 234 & $14.53 \%$ & 2013 & 467 & $28.99 \%$ \\
\hline 2011 & 338 & $20.98 \%$ & 合计 & 1611 & $100.00 \%$ \\
\hline
\end{tabular}

研究成果主要由基金资助论文数来体现，一定时间内 的档案基金论文数量可以大体反映该阶段档案学科研水平 
和科研状况。档案学基金论文年度分布情况见表 1 : 2009-2013 年间共发表档案学基金论文 1611 篇, 平均每年 发文 322 篇, 2013 年比 2009 年多 300 篇, 档案基金论文 数量呈现逐年快速上升趋势。

表 2 基金论文资助数量分布表

\begin{tabular}{|c|c|c|c|c|}
\hline 基金资助数量 & 一项 & 二项 & 三项 & 四项以上 \\
\hline 论文篇数 & 1294 & 248 & 61 & 8 \\
\hline 论文总数比例 & $80 \%$ & $15 \%$ & $4 \%$ & $1 \%$ \\
\hline
\end{tabular}

通过对基金资助论文数量的分析, 可对档案基金论文 选题的科技含量、学术水平、科技创新和成果影响进行科 学预测。2009-2013 年间档案学基金论文获得的基金资助的 数量见表 2: 1611 篇论文中有 1294 篇论文获得一项基金的 资助, 占论文总数的 $80 \% ， 248$ 篇论文获得两项基金的资 助, 61 篇论文获得三项基金的资助。档案基金论文大部分 只获得一项基金资助, 能得到两项以上基金资助的论文很 少, 需要加强多部门、多系统的科研合作。

表 3 基金论文数量、级别及年度分布表

\begin{tabular}{|c|c|c|c|c|c|c|c|}
\hline \multicolumn{2}{|c|}{ 级别 } & 2009 & 2010 & 2011 & 2012 & 2013 & 合计 \\
\hline \multirow{2}{*}{$\begin{array}{c}\text { 国 } \\
\text { 家 }\end{array}$} & 社科 & 26 & 43 & 54 & 77 & 101 & 301 \\
\cline { 2 - 8 } & 自科 & 11 & 2 & 5 & 3 & 7 & 28 \\
\cline { 2 - 9 } & 其他 & 7 & 20 & 27 & 27 & 40 & 121 \\
\hline \multicolumn{2}{|c|}{ 省部级 } & 74 & 111 & 182 & 236 & 283 & 886 \\
\hline 地厅级 & 21 & 31 & 47 & 58 & 40 & 197 \\
\hline 高校级 & 39 & 49 & 76 & 78 & 86 & 328 \\
\hline \multicolumn{2}{|c|}{ 其他 } & 3 & 6 & 10 & 3 & 3 & 25 \\
\hline \multicolumn{2}{|c|}{ 合计 } & 181 & 262 & 401 & 482 & 560 & 1886 \\
\hline
\end{tabular}

从获得资助基金的级别统计，可以对基金资助课题的 科研价值、科研水平做出客观的分析与评价, 1611 篇论文 在 2009-2013 年间共获得 1886 项基金的资助（见表 3), 档 案学基金资助机构主要为各级政府部门, 国家级基金 450 篇, 省部级基金 886 篇, 地厅级基金 197 篇, 高校级基金 328 篇, 其他和难以判断基金 25 篇, 主要有 2009 年洛克 菲勒基金会档案中心(RAC) 资助的中国现代医学初建时期 的布局: 洛克菲勒基金会的影响, 以及 2011 年美国中华医 学基金会对:老协和档案保护与研究。还有部分是行业协会 的资助, 如中国房地产估价师与房地产经纪人学会立项课 题“估价档案管理要求” 等, 都是出现的新动态。中国科学 院地理科学与资源研究所资源与环境信息系统国家重点实 验室等多个单位参加的 “公益性行业科研专项项目
(200909110): : 环保档案信息资源共享框架构建关键技术与 示范研究”有 7 篇论文却难以判断级别。近年来省部级基金 论文资助力度加大, 各高校也加强了对档案学基础研究的 支持。基金论文的资助呈现持续快速增长，基金资助的数 量有了大幅提高, 并一直呈上升趋势。

\section{2 档案学基金论文的期刊分布}

研究档案基金论文的来源期刊, 可以了解档案基金研 究的空间分布特点, 有助于掌握档案基金论文的发文规律。 依据布拉德定律关于文献的集中与离散分布规律, 即在一 定时期内, 某一学科所涉及到的研究内容通常集中分布于 数量不多但效率较高的 $\mathrm{n}$ 种期刊上, 这些期刊为该研究内 容的核心密集区, 它们所刊载的论文至少达到该研究文献 总量的三分之一[3]。2008-2013 年收录基金论文篇数前 8 位的都是档案学核心期刊 (见表 4), 《兰台世界》发文最 多, 刊发基金论文 240 篇, 占 $14.9 \%$, 档案学 10 种核心期 刊全部榜上有名, 仅《山西档案》和《中国档案》的发文 量排位稍后, 刊载 30 篇文献以上的有 12 种, 刊载 12 篇 以上的有 16 种, 共载文 973 篇, 占发文总量的 $60.40 \%$ 。 档案学核心期刊和档案学期刊是档案学基金论文主要发文 期刊, 有力支持和推进了档案学研究。

表 4 基金论文的期刊分布表

\begin{tabular}{|c|c|c|}
\hline 刊名 & 篇数 & 比例 (\%) \\
\hline 兰台世界* & 240 & $14.90 \%$ \\
\hline 档案学通讯* & 155 & $9.62 \%$ \\
\hline 档案管理* & 96 & $5.96 \%$ \\
\hline 档案学研究* & 92 & $5.71 \%$ \\
\hline 档案与建设* & 57 & $3.54 \%$ \\
\hline 北京档案* & 54 & $3.35 \%$ \\
\hline 浙江档案* & 42 & $2.61 \%$ \\
\hline 档案* & 39 & $2.42 \%$ \\
\hline 黑龙江档案 & 39 & $2.42 \%$ \\
\hline 办公自动化 & 36 & $2.23 \%$ \\
\hline 山西档案* & 34 & $2.11 \%$ \\
\hline 云南档案 & 32 & $1.99 \%$ \\
\hline 学理论 & 18 & $1.12 \%$ \\
\hline 机电兵船档案 & 14 & $0.87 \%$ \\
\hline 中国档案* & 13 & $0.81 \%$ \\
\hline 档案时空 & 12 & $0.74 \%$ \\
\hline
\end{tabular}

注: 带 *号的为档案学核心期刊。《档案》2011 版退出档案 学核心期刊。 


\section{3 档案学基金论文作者统计分析}

\subsection{1 作者发文情况统计分析}

对档案基金论文作者进行统计分析, 可以发现档案基 金论文高产作者, 掌握其核心作者群。档案基金论文作者 的发文情况见表 5, 在 1611 篇基金论文中, 发表一篇论文 的 594 人，发文 2 篇的 155 人，发文 3 篇的 50 人，发文 4 篇的 35 人，发文 5 篇以上的基金论文有 417 篇。1017 篇 基金论文为发表 2 篇以上的作者完成，达到 $63.13 \%$ 。

表 5 基金论文作者发文统计表

\begin{tabular}{|l|c|c|c|c|c|}
\hline 发文数 & 1 & 2 & 3 & 4 & 5 及以上 \\
\hline 作者数 & 594 & 310 & 150 & 140 & 417 \\
\hline 比例 & $36.87 \%$ & $19.24 \%$ & $9.31 \%$ & $8.69 \%$ & $25.88 \%$ \\
\hline
\end{tabular}

根据普赖斯定律, 计算公式为: $\mathrm{M}=0.749 \sqrt{(N \max )}$ 。 式中, $\mathrm{M}$ 为发表的论文篇数, $\mathrm{Nmax}$ 为所统计的年限中发 表文章最多的那位作者的论文数, 那些发表论文数在 $\mathrm{M}$ 篇 以上的作者, 为高产作者 [4]。基金论文发文量 5 篇以上的 作者 56 人, 发文量 417 篇, 占发文总量的 $25.88 \%$ 。发文 量达到 5 篇以上的作者有: 赵彦昌 18 篇, 周林兴 15 篇、 陈忠海和刘东斌 14 篇, 丁华东 13 篇, 谢小红 12 篇, 华林、 吴雁平和周耀林 11 篇, 倪丽娟和吴加琪 10 篇, 吕元智和 马仁杰 9 篇, 曹航、陈祖芬、陈辉、黄晓丹、聂云霞、任 越和项文新 8 篇, 程妍妍、刘迎红、连红和徐海静 7 篇, 毕建新、市咸杰、曹宇、段荣婷、黄霄羽、金凡、王萍、 王新才、魏顺光、许兴华、曾伟忠、张锐、张世林、张文 浩、赵淑梅和朱兰兰 6 篇, 胡䒯、鲍勇、邸家琴、贾玲、 巨珺、梁孟华、刘冬梅、鲁德武、彭志斌、苏君华、唐婧、 王玉龙、肖武云、杨毅、张皓和诸云强 5 篇。这批档案基 金论文核心作者已成为档案学研究的重要力量, 在一定程 度上代表了档案学研究的趋势和热点。人均发文量达到 7.4 篇, 也反映了档案学基金研究要求比较高, 管理比较规范。

2.3 .2 作者合作情况分析

表 6 基金论文作者合著情况统计表

\begin{tabular}{|l|r|r|r|r|r|}
\hline 发文形式 & \multicolumn{1}{|l|}{ 独撰 } & \multicolumn{1}{l|}{ 2人 } & \multicolumn{1}{l|}{ 3人 } & 4 人以上 & \multicolumn{1}{l|}{ 合计 } \\
\hline 发文篇数 & 918 & 417 & 167 & 109 & 1611 \\
\hline 比例 $(\%)$ & $56.98 \%$ & $25.88 \%$ & $10.37 \%$ & $6.77 \%$ & $100.00 \%$ \\
\hline
\end{tabular}

合著率是指一定时期内相关文献的合著论文数占该时 期论文总数的比率 [5], 论文作者的合著率是反映作者合作 程度的重要指标。本次统计的 1611 篇论文中, 单一作者
发文 918 篇, 占论文总数的 $56.98 \% ; 2$ 人作者发文 417 篇, 占论文总数的 $25.88 \% ; 3$ 人以上作者发文 167 篇, 占论文 总数的 $10.37 \%$; 4 人及以上合著 109 篇, 占论文总数的 $6.77 \%$ 。(见表 6)，1161 篇论文中，合著的论文 693 篇，占 论文总数的 $43.02 \%$, 即合著率为 $43.02 \%$, 作为基金论文, 研究仍以个体研究为主, 合作程度偏低。今后要加强多学 科的交叉与合作, 提高合作水平和科研质量。我国档案学 研究与国外合作研究很少, 需加强国外先进研究方法借鉴, 从而推进和提高科研的深度与广度。

\subsection{3 作者地区分析}

对基金论文作者进行地区分布统计，可以了解档案基 金研究的地理分布状况, 以及档案基金研究队伍现状。除 新疆、西藏、宁夏, 以及台湾、香港、澳门以外, 1611 篇 基金论文分布于我国的 25 个省（市)，档案基金研究地区 分布范围广但不均衡 (见表 7)。把中科院和央企等归类为 其他，基金论文发文超过 100 篇的地区是：河南、江苏、 北京、黑龙江、上海 5 省, 达到 50 篇以上的省份有辽宁、 安徽、湖南、河北、浙江、广东、云南、湖北 8 省。这些 地区是我国档案学基金研究较活跃, 成果丰富。档案学基 金论文比较集中在社会经济发达的东部地区，对我国西部 地区可以通过政策支持和基金扶持支持档案学研究。

表 7 基金论文作者地区分布统计表

\begin{tabular}{|c|c|c|c|c|c|}
\hline 地区 & 作者 & 地区 & 作者 & 地区 & 作者 \\
\hline 河南 & 212 & 广东 & 55 & 天津 & 17 \\
\hline 江苏 & 171 & 云南 & 55 & 陕西 & 12 \\
\hline 北京 & 149 & 湖北 & 53 & 海南 & 8 \\
\hline 黑龙江 & 132 & 江西 & 46 & 山西 & 7 \\
\hline 上海 & 122 & 广西 & 45 & 内蒙古 & 1 \\
\hline 辽宁 & 80 & 四川 & 43 & 其他 & 28 \\
\hline 安徽 & 67 & 山东 & 32 & 不详 & 18 \\
\hline 湖南 & 65 & 福建 & 28 & 合计 & 1611 \\
\hline 河北 & 62 & 重庆 & 24 & & \\
\hline 浙江 & 58 & 吉林 & 21 & & \\
\hline
\end{tabular}

\section{4 档案学基金论文机构统计分析}

对作者机构分布的分析, 既可以了解在档案学基金项 目研究中的队伍分布状况, 又可以了解我国各档案学研究 机构的研究能力。论文作者大部分来自高校 (见表 8), 1437 人来自高校系统, 占总数的 $89.20 \%$, 其中, 有 577 人来自 高校的档案馆, 464 人来自高校的其他部门, 主要是高校 教师和机关及院系的兼职档案管理人员等, 396 人来自高 
校的信息管理学院; 公共档案馆的作者人数为 76 人, 占 $4.72 \%$; 科研院所 37 人, 占 $2.3 \%$, 其他企事业单位 52 人, 占 $3.23 \%$; 未能判断所属单位的有 9 人。高校档案学基金 论文的主要研究力量, 公共档案馆和科研院所等单位的科 研有待加强。

表 8 基金论文作者机构统计表

\begin{tabular}{|c|c|c|}
\hline 机构类型 & 作者数量 & 比例 $(\%)$ \\
\hline 高校档案馆 & 577 & $35.82 \%$ \\
\hline 高校其他部门 & 464 & $28.80 \%$ \\
\hline 高校信息管理学院 & 396 & $24.58 \%$ \\
\hline 公共档案馆 & 76 & $4.72 \%$ \\
\hline 其他企事业单位 & 52 & $3.23 \%$ \\
\hline 科研院所 & 37 & $2.30 \%$ \\
\hline 不详 & 9 & $0.56 \%$ \\
\hline 合计 & 1611 & $100.00 \%$ \\
\hline
\end{tabular}

分析档案基金资助项目的机构分布, 可以了解档案研 究机构的活跃程度、研究实力和科研水平。发表基金论文 20 篇以上的单位共有 14 个 (见表 9), 发文 544 篇, 占总 发文量的 $33.77 \%$; 发文较多的单位分别是黑龙江大学 86 篇、上海大学 61 篇、中国人民大学 55 篇等; 发文 15 篇以 上的单位有上海师范大学 19 篇, 河北大学 18 篇, 开封市 档案局 16 篇, 东南大学、吉林大学和誉阳市档案局 15 篇; 发文量 10 篇以上的单位共 37 个, 发文 838 篇, 达 $52 \%$ 。 在发文量较多的机构中形成了一批核心科研团队, 如黑龙 江大学发文量 5 篇以上的作者有 8 人, 发文量 30 篇以上的 机构都有 2 人以上发文量达 5 篇以上。这批核心研究机构 和核心学者一般都获有较高级别的基金资助项目。除开封 市档案局和钅阳市档案局外, 全部来自高校, 表明高校具 有强大的科研实力, 需要提高从事档案实际工作人员的科 研能力。

\section{3. 结语}

尽管在统计过程中有不周全之处 (仅分析第一作者), 在统计指标设定中也有些粗陃, 因统计时间差导致 2013 年 的统计有些遗漏等。但运用文献计量学的研究方法对档案 基金论文进行分析, 整体上能反映档案基金研究学术研究 的实际情况。通过对档案基金论文的回溯性研究, 与《分 析》作比较, 近年来档案基金资助数量增多, 基金论文增 长很快, 获多项基金资助的项目增加, 国家级基金资助稳 定, 省市级及高校加大对档案学基金资助; 档案核心期刊 是档案学基金资助论文的主要发刊期刊; 发表 2 篇以上基 金论文的作者大幅增加，基金论文合作合著情况变化不大，
基金论文作者的地理分布依然不平衡; 档案基金论文发文 更集中趋向高校, 公共档案馆和科研院所等企事业单位的 基金论文偏低。档案学基金资助研究具有科学性、指导性 和前瞻性，档案基金资助对档案工作带来了新的机遇和挑 战。

表 9 基金论文作者机构分布表

\begin{tabular}{|c|c|c|c|}
\hline 序号 & 单位 & 发文 & 5 篇以上作者 \\
\hline 1 & 黑龙江大学 & 86 & $\begin{array}{c}\text { 倪丽娟 } 10 、 \text { 陈辉 } 8 \text { 、任越 8、刘迎 } \\
\text { 红 7、徐海静 7、张锐 6、张文浩 6、 } \\
\text { 邸家琴 } 5\end{array}$ \\
\hline 2 & 上海大学 & 61 & 丁华东 13 、曹航 8、王玉龙 5 \\
\hline 3 & 中国人民大学 & 55 & 黄霄羽 6、张世林 6 \\
\hline 4 & 辽宁大学 & 47 & 赵彦昌 18 、曹宇 6、赵淑梅 6 \\
\hline 5 & 云南大学 & 45 & 华林 11、胡莹 5、杨毅 5 \\
\hline 6 & 武汉大学 & 41 & 周耀林 11 、王新才 6 \\
\hline 7 & 南昌大学 & 33 & $\begin{array}{c}\text { 周林兴 15、聂云霞 8、曾伟忠 6、 } \\
\text { 苏君华 } 5\end{array}$ \\
\hline 8 & 苏州大学 & 30 & 项文新 8 \\
\hline 9 & 郑州大学 & 29 & 陈忠海 14、金凡 6 \\
\hline 10 & 南京大学 & 28 & \\
\hline 11 & 安徽大学 & 23 & 马仁杰 9 \\
\hline 12 & 南京政治学院 & 22 & 程妍妍 7、段荣婷 6 \\
\hline 13 & $\begin{array}{c}\text { 郑州航空工业 } \\
\text { 管理学院 }\end{array}$ & 22 & 朱兰兰 6 \\
\hline 14 & 中原工学院 & 22 & 黄晓丹 8 \\
\hline 合计 & & 544 & \\
\hline
\end{tabular}

参考文献(References)

[1] Gao fan, Wang Huixiang. The output of fund theses research and quantitative analysis of information in Library Science in China. Library and information work, 2004,(10):12-16.

[2] Liu Hongzhu, Hua Weina, Yue Quan. Statistics and Analysis archives fund theses in our country 1990-2007. files and construction,2008,11:11-14.

[3] Qiu Junping. Information metrology. Wuhan: Wuhan University press,2007:105-106.

[4] Ding Xuedong. The literature metrology foundation. Beijing: Peking University press, 1992:220-232.

[5] Xing Jianhua, Wang Zhuoyun. Analysis of 2000 2006 theses of author group. China journals of science and technology research,2008,(3):398-401. 